\title{
Incorporation of Elastin to Improve Polycaprolactone-Based Scaffolds for Skeletal Muscle via Electrospinning
}

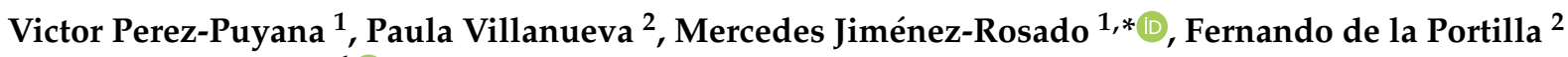 \\ and Alberto Romero ${ }^{1}$ (D) \\ 1 Departamento de Ingeniería Química, Facultad de Química, Universidad de Sevilla, 41012 Sevilla, Spain; \\ vperez11@us.es (V.P.-P.); alromero@us.es (A.R.) \\ 2 Institute of Biomedicine of Seville (IBiS), "Virgen del Rocío" University Hospital, IBiS, CSIC/University of \\ Seville, 41013 Sevilla, Spain; paulavg1995@gmail.com (P.V.); fportilla@us.es (F.d.1.P.) \\ * Correspondence: mjimenez42@us.es; Tel.: +34-954-557-179
}

Citation: Perez-Puyana, V.;

Villanueva, P.; Jiménez-Rosado, M.; de la Portilla, F.; Romero, A. Incorporation of Elastin to Improve Polycaprolactone-Based Scaffolds for Skeletal Muscle via Electrospinning. Polymers 2021, 13, 1501. https:// doi.org/10.3390/polym13091501

Academic Editor: Paolo Ferruti

Received: 23 April 2021

Accepted: 5 May 2021

Published: 6 May 2021

Publisher's Note: MDPI stays neutral with regard to jurisdictional claims in published maps and institutional affiliations.

Copyright: (c) 2021 by the authors. Licensee MDPI, Basel, Switzerland. This article is an open access article distributed under the terms and conditions of the Creative Commons Attribution (CC BY) license (https:// creativecommons.org/licenses/by/ $4.0 /)$.

\begin{abstract}
Skeletal muscle regeneration is increasingly necessary, which is reflected in the increasing number of studies that are focused on improving the scaffolds used for such regeneration, as well as the incubation protocol. The main objective of this work was to improve the characteristics of polycaprolactone (PCL) scaffolds by incorporating elastin to achieve better cell proliferation and biocompatibility. In addition, two cell incubation protocols (with and without dynamic mechanical stimulation) were evaluated to improve the activity and functionality yields of the regenerated cells. The results indicate that the incorporation of elastin generates aligned and more hydrophilic scaffolds with smaller fiber size. In addition, the mechanical properties of the resulting scaffolds make them adequate for use in both bioreactors and patients. All these characteristics increase the biocompatibility of these systems, generating a better interconnection with the tissue. However, due to the low maturation achieved in biological tests, no differences could be found between the incubation with and without dynamic mechanical stimulation.
\end{abstract}

Keywords: elastin; electrospinning; scaffolds; skeletal muscle cells

\section{Introduction}

Regenerative medicine and specifically tissue engineering have grown exponentially in the number of publications, with the latter being one of the advances in biomedicine with greater impact [1,2]. This growth is due to the creation of new processing protocols that improve the quality of biomaterials [3]. For example, Kobayashi et al. proposed a standard protocol to prepare platelet-rich fibrin membranes [4], Zuidema et al. standardized the protocol for the correct rheological characterization of hydrogels for tissue engineering [5], and Xing et al. evaluated a quantity-controllable protocol for constructing individual tissue-engineered grafts [6].

In this field, skeletal muscle regeneration or substitution has increased its interest due to the large number of accidents and diseases that cause loss of muscle or muscle mass [7]. However, the techniques proposed to date are limited, since they not allow restoring the full functionality of the replaced muscle [8]. The failure of these techniques is usually due to the fact that the muscle cells are incubated ex vivo in a static manner, without undergoing the mechanical stimulation to which they are accustomed within the human body. This inactivity causes necrotic areas in the regenerated muscle and cells, which do not fulfill their functionality once settled in the patient [9]. Therefore, new protocols are being investigated, where muscle cells are dynamically stimulated during their incubation, improving their proliferation and differentiation. This is achieved using bioreactors that subject the cells to mechanical stimulation, recreating the conditions of muscle tissue in vivo [10,11]. However, this regeneration cannot be carried out directly on loose cells; therefore, a scaffold is necessary to support them. In this way, the cells are introduced into the scaffolds, which 
support the mechanical stimulation of the bioreactor and transfer it to the cells [12]. Thus, scaffolds must have the mechanical properties requested by the bioreactor, in addition to morphological properties suitable for the interconnection and proliferation of cells [13]. The biodegradability of the scaffolds is also important, since it must disappear once the muscle cells can fulfil their functionalities by themselves. Therefore, the development of a biomaterial and, specifically in our case, a scaffold for tissue engineering, is not based solely on the study of its manufacturing process. A complete evaluation of the scaffold must be carried out according to the type and duration of its contact with human tissue. In general, it is necessary to make a chemical and compositional characterization of the material. Moreover, biocompatibility must also be evaluated. Therefore, a biological evaluation of the material is required. These biological tests are based on in vitro and in vivo test methods, together with animal models. Such tests provide a good approximation for evaluating the behaviour of these materials [14].

Regarding the raw materials used to make the scaffolds, different polymers have been investigated [15]. For example, Riboldi et al. utilized polyester urethane membranes [16] and Patricio et al. characterize different polycaprolactone (PCL)/polylactic acid (PLA) scaffolds [17]. Among them, PCL has great potential due to its mechanical and morphological characteristics [18,19], although its surface properties, such as contact angle, do not confer good cell viability, unless it is combined with another biopolymer, such as alginate [20,21], collagen [22,23] or chitosan [24].

As a further innovation, for our study, dynamic stimulation provided by a bioreactor was added to this attempt to produce skeletal muscle in vitro. In addition, a polymeric combination of PCL/elastin-based scaffolds fabricated by electrospinning was used as support for muscle cells. Therefore, this work proposes the development of polymer-based scaffolds using a hybrid system developed from PCL and elastin via electrospinning. The approach adopted is the combination of PCL with elastin in order to tune the properties of PCL fibers to make them suitable for tissue engineering applications. To achieve this objective, a physicochemical, morphological and mechanical evaluation of the hybrid scaffolds was performed. In addition, a biological assessment through in vitro and in vivo studies was also carried out.

\section{Materials and Methods}

\subsection{Materials}

Elastin protein from bovine neck ligament was used as natural polymer (Sigma Aldrich, Steinheim, Germany). On the other hand, the synthetic polymer selected was poly( $\varepsilon$-caprolactone) (PCL) with a molecular weight of $45,000 \mathrm{~g} / \mathrm{mol}$. The solvent chosen for the hybrid solutions was 1,1,1,3,3,3-hexafluoro-2-propanol (HFIP). Both reagents were also purchased from Sigma Aldrich.

\subsection{Electrospining Process}

First of all, a polymer solution with PCL and elastin was prepared using 16 and $4 w / v \%$, respectively. These concentrations were selected because in previous studies it was demonstrated that a 4:1 ratio of PCL:elastin is the most optimal [25]. The solution was produced with HFIP as solvent at room temperature by stirring for ca. $24 \mathrm{~h}$ using a magnetic stirrer, before the electrospinning process. Once the solution was prepared, the electrospinning process was carried out in vertical mode with the following conditions: $14 \mathrm{kV}$ (voltage), $0.4 \mathrm{~mL} / \mathrm{h}$ (flow rate), $14 \mathrm{~cm}$ (needle-collector distance), $25^{\circ} \mathrm{C}$ and $40 \%$ (temperature and humidity, respectively). The syringe used was a $10 \mathrm{~mL}$ syringe (with an $18 \mathrm{G}$ stainless steel needle). It was mentioning that the parameters used for the processing of PCL membranes utilized for comparison are similar. 


\subsection{Characterization of Nanofibrous Scaffolds}

\subsubsection{Morphological Evaluation}

The microscopy examination of the scaffolds was assessed with a XL 30 instrument (XL Series, Philips, Amsterdam, The Netherlands) at $15 \mathrm{kV}$. The samples were previously covered with a nanofilm of $\mathrm{Au}$ in a high-resolution sputter coater to improve the quality of the micrographs. A free digital processing software package, ImageJ, was used to determine the membrane porosity as well as the size of the fibers. Furthermore, the atomic composition of the scaffolds was examined with the energy dispersive spectroscopy capability (EDAX) of the scanning electron microscopy (SEM) equipment using an EDAX $\mathrm{Si}(\mathrm{Li})$ detector at an acceleration voltage of $5 \mathrm{kV}$.

\subsubsection{Physicochemical Evaluation}

A physicochemical characterization was carried out with an iS50 ATR-FTIR spectrophotometer (Nicolet, Waltham, MA, USA). The different spectra were collected in the range of 4000-500 $\mathrm{cm}^{-1}$. In addition, the scaffolds' wettability and hydrophobicity were assessed by water contact angle (WCA) measurements using a Drop Shape Analyser (Krüss, Hamburg, Germany). Both WCA values of the right and left sides of water droplets (volume of $5 \mu \mathrm{L}$ approximately) were measured and the average value was calculated.

\subsubsection{Mechanical Evaluation}

Tensile tests were performed using an ElectroForce 3200 (TA Instruments, New Castle, DE, USA), evaluating the evolution of the tensile load with the applied strain. The extensional rate was $0.1 \mathrm{~mm} \mathrm{~s}^{-1}$ at $20^{\circ} \mathrm{C}$. From the different measurements, three parameters were obtained: maximum stress, strain at break and Young's modulus.

\subsubsection{Biological Evaluation}

The scaffolds were biologically evaluated to assess cell behaviour. The cells used were rat skeletal myoblasts obtained from Rattus norvegicus L6 cell line (ATCC ${ }^{\circledR}$ CRL-1458 ${ }^{\mathrm{TM}}$ ) and were cultured in an incubator at $37^{\circ} \mathrm{C}$ in the presence of $5 \% \mathrm{CO}_{2}$. The growth medium used was Minimum Essential Medium $\alpha$ (12571-063, Gibco, Waltham, MA, USA) supplemented with $10 \%$ fetal bovine serum (FBS, Sigma) and 1\% penicillin-streptomycin (P/S, 15140-122, Gibco). After the cells reached $85-90 \%$ of confluence, they were sub-cultured using trypsinEDTA at $0.05 \%\left(25300-062\right.$, Gibco) and $20 \times 10^{6}$ cells were seeded in each scaffold with growth medium. The scaffolds were cultured in a TC3 bioreactor (EBERS Medical Technology SL, Zaragoza, Spain) to be mechanically stimulated, inside the incubator, for 14 days (called dynamic scaffolds). After 7 days, the culture medium was changed to a differentiating medium of DMEM/high glucose with FBS at $2 \%$ and P/S at $1 \%$. Static scaffolds (without mechanical stimulation) were used as control.

Every 72 h, a viability test (in vitro evaluation) was performed using Presto Blue (PrestoBlue ${ }^{\mathrm{TM}}$ Cell Viability Reagent, Invitrogen, Waltham, MA, USA) due to the presence of resazurin, a cell viability indicator, in its formulation.

Fourteen days after the beginning of the experiment, the scaffolds were extracted from the incubator and inserted in the animal model. The in vivo study encompassed 10 Wistar rats, in which two scaffolds (a dynamic scaffold and a static scaffold) were inserted and extracted after 30 days.

The scaffolds were then processed and stained with hematoxylin-eosin (H\&E) (GHS316 Hematoxylin Solution, Gill No. 3; HT110116 500 ML: Eosin Y Solution, Sigma). The histological analysis was performed following Knightly's classification [26], considering the reaction as slight (1 point, $<25 \%)$, moderate ( 2 points, $25-75 \%)$ or severe $(>75 \%)$. The variables evaluated were: acute inflammation, chronic inflammation, collagen deposition, fibroblast activity and neovascularization. In addition, the scaffolds were immunohistochemically stained with myogenin (Ab1835, Abcam, Cambridge, UK) to detect the degree of cell differentiation. The microscopy images were taken with the BX-61 microscope (Olympus, Tokyo, Japon) at $20 \times$. 


\subsection{Ethical Considerations}

This project is in the category of the Institutional Animal Care and Use Committee (IACUC) classification, since it includes procedures that cause or induce moderate pain, stress or discomfort, which are inhibited or eliminated with the required analgesics or anesthetics [27].

During the experimental period of this research project, the animals were treated according to the Council of Europe agreements for the protection of the animal experimental models used (Directive of the Council of Europe 86/609/EEC). In the different work procedures, the replacement and reduction of the number of animals was guaranteed, in addition to their housing, care and use. The pain, suffering and stress that these animals could potentially develop was minimized as much as possible.

The justification for the use of this experimental model is based on the absence of another type of procedure that allows achieving the expected results.

\subsection{Statistical Analysis}

At least three replicates were carried out for each measurement. Statistical analyses were performed with $t$ tests and one-way analysis of variance $(p<0.05)$ using PASW Statistics for Windows (Version 18: SPSS, Chicago, IL, USA). Standard deviations were calculated for selected parameters.

\section{Results \& Discussion}

\subsection{Morphological Evaluation of Nanofibrous Scaffolds}

Figure 1 shows the SEM images of electrospun mats obtained from the combination of PCL and elastin at different magnifications. Figure 1A shows a general overview of the microstructure of the obtained scaffold, whereas Figure 1B shows a better view of the fibers. In these micrographs, homogeneous fibers can be observed. Furthermore, Figure 1 also shows the fiber size distribution of the studied system (Figure 1C). The scaffold had a Gaussian distribution with respect to a central value (ranging between 200 and $300 \mathrm{~nm}$ ). Thus, the PCL-elastin scaffold showed a homogeneous distribution towards that central value, with a mean fiber diameter of $269 \mathrm{~nm}$ (Table 1). This mean fiber diameter is slightly lower than the values obtained in other studies $[28,29]$. It is interesting to point out that smaller fiber sizes are more suitable to obtain a larger surface for cell adhesion [30]. In this way, PCL-elastin scaffolds could improve the adhesion achieved by PCL scaffolds with a larger fiber diameter $(451 \mathrm{~nm})$. In addition to fiber size, the alignment of the fibers was also calculated, showing a relatively aligned structure with a general alignment of 50\% (Table 1). This slight alignment could be beneficial for the growth and interconnection of cells in a given orientation, which is interesting for some muscles, such as myotubes [31] or endothelium [32].
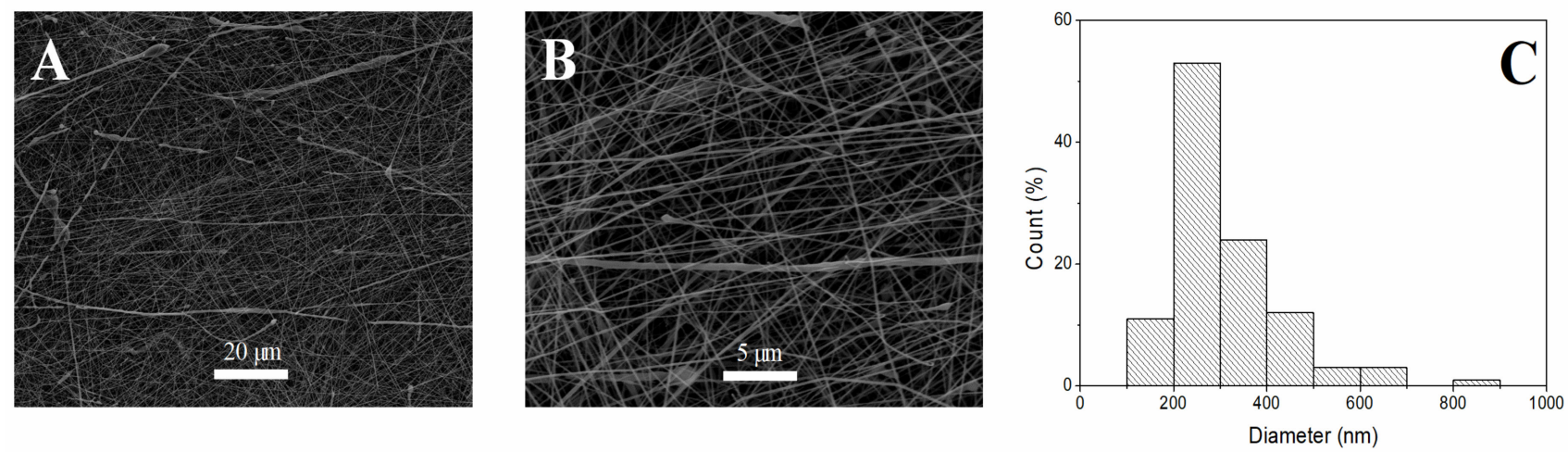

Figure 1. SEM images of PCL/elastin scaffolds at different magnifications: (A) $1000 \times$ and (B) $4000 \times$. The fiber size distribution was also included (C). 
Table 1. Mean fiber diameter, alignment, protein content, contact angle, Young's modulus, strain at break and maximum stress values of PCL/elastin scaffolds. Some of the parameters obtained for PCL scaffolds were also included as reference. * means that there is no data reported

\begin{tabular}{|c|c|c|c|c|c|c|c|}
\hline System & $\begin{array}{c}\text { Fiber } \\
\text { Diameter }(\mathrm{nm})\end{array}$ & $\underset{(\%)}{\text { Alignment }}$ & $\begin{array}{c}\text { Protein } \\
\text { Content (\%) }\end{array}$ & $\begin{array}{c}\text { Contact Angle } \\
\left({ }^{\circ}\right)\end{array}$ & $\begin{array}{c}\text { Young's } \\
\text { Modulus (MPa) }\end{array}$ & $\begin{array}{c}\text { Strain at } \\
\text { Break }(\%)\end{array}$ & $\begin{array}{c}\text { Maximum } \\
\text { Stress (MPa) }\end{array}$ \\
\hline $\begin{array}{l}\text { PCL-Elastin } \\
\text { PCL }\end{array}$ & $\begin{array}{l}269 \pm 84 \\
451 \pm 62\end{array}$ & $50 \pm 7$ & $2.5 \pm 0.5$ & $\begin{array}{c}67.5 \pm 3.2 \\
102 \pm 11\end{array}$ & $\begin{array}{c}120.0 \pm 28.5 \\
35 \pm 2.4\end{array}$ & $\begin{array}{c}25.3 \pm 4.2 \\
55 \pm 6.7\end{array}$ & $\begin{array}{c}18.1 \pm 3.9 \\
10.6\end{array}$ \\
\hline
\end{tabular}

Furthermore, the presence of protein in the network of the fibrous membrane can be identified by the presence of nitrogen in it. Thus, an EDAX analysis was performed with the SEM images to confirm that the electrospun fibers contained proteins in their structure. The nitrogen present in the surface obtained from the EDAX profile is shown in Table 1, with an average value of $2.51 \%$. This amount of protein contributes to energy barriers that must be overcome during cell adhesion, improving the biocompatibility of scaffolds [33].

\subsection{Physicochemical Evaluation of Nanofibrous Scaffolds}

The presence of protein in the structure of the scaffold can also be analyzed from the FTIR profile (Figure 2). The spectrum presented a profile with the characteristic peaks of $\mathrm{PCL}$, together with the typical bands of proteins. PCL is responsible for two important areas: bands at 2950 and $2860 \mathrm{~cm}^{-1}$ (A) related to the $\mathrm{CH}_{2}$ symmetrical and asymmetrical stretching and a sharp band that appears at $1725 \mathrm{~cm}^{-1}$ (B), associated with carbonyl stretching [34]. In addition to this, the bands from elastin (protein) are: a broad area at ca. $3280 \mathrm{~cm}^{-1}\left(\mathrm{~A}^{\prime}\right)$ associated with $\mathrm{N}-\mathrm{H}$ stretching (amide A signal), attenuated due to the low concentration of protein compared to PCL, and bands at 1635 and $1525 \mathrm{~cm}^{-1}\left(\mathrm{~B}^{\prime}\right)$ related to carbonyl stretching and C-N stretching of amides, respectively [35,36].

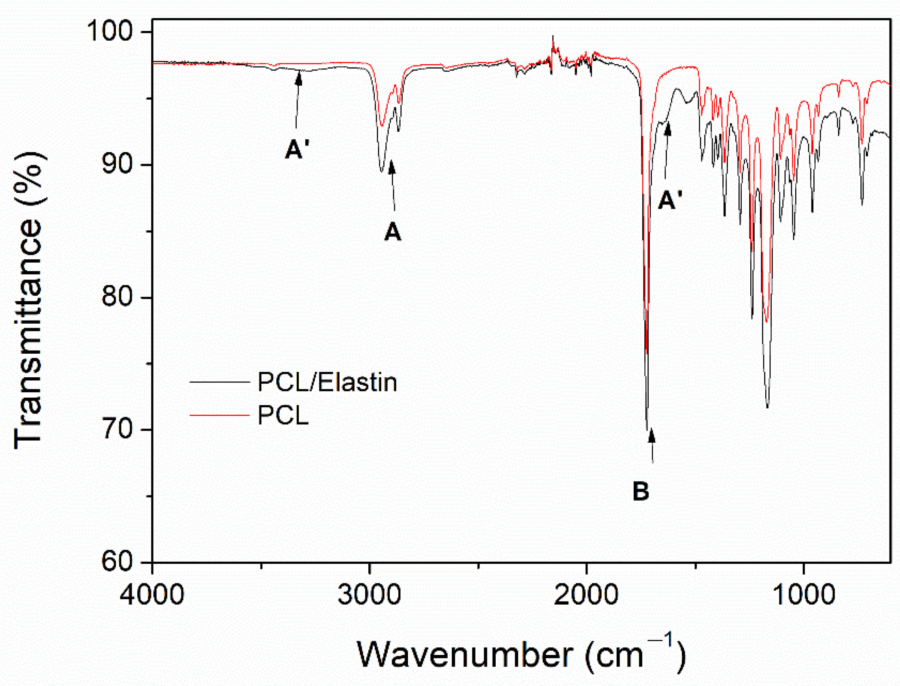

Figure 2. FTIR profile of PCL/elastin and PCL scaffolds.

The wettability of the obtained scaffolds was also measured, as is observed in Table 1, in order to study their hydrophobicity. The hybrid system presented a contact angle of $c a$ $68^{\circ}$, much lower than the value of pure PCL systems, which are in the range of $90-100^{\circ}$ [37]. This value allows determining that the scaffold is hydrophilic according to the studies of Kubiak and Mathia [38]. This hydrophilic character could be due to the presence of elastin on the surface of the fibers, which is much more hydrophilic than PCL. The hydrophilicity acquired due to the inclusion of elastin (protein) is suitable for cell adhesion [39]. According to the obtained value, it can be confirmed that the presence of elastin produced a decrease 
in the contact angle and, therefore, a more hydrophilic system that could improve its cell adhesion and proliferation. This behaviour is due to the influence of the protein on the energy barriers, as was previously commented.

\subsection{Mechanical Characterization of Nanofibrous Scaffolds}

The analysis of the different parameters obtained from the strain-stress curves is shown in Table 1. All the systems showed a similar behaviour, with a linear increase in the strain/stress profile until a maximum value is reached, since when a slight decrease of the slope take place until the sample is broken, with the subsequent decrease in the profile (profile not shown). According to the results shown, the decrease of the fiber size showed in Section 3.1 is not correlated with the obtained mechanical properties. As a general fact, the addition of elastin to PCL scaffolds produced a reinforcement of the structure, based on the increase in both Young's modulus and maximum stress with respect to the PCL reference system. However, the produced system is less deformable, as is shown by the decrease in the strain at break, compared to the values obtained for pure PCL scaffolds [37].

\subsection{Biological Evaluation of Nanofibrous Scaffolds}

\subsection{1. "In Vitro" Evaluation}

The evolution of cell viability during the 14 days of incubation in non-stimulated (static) and stimulated (dynamic) scaffolds is shown in Figure 3.

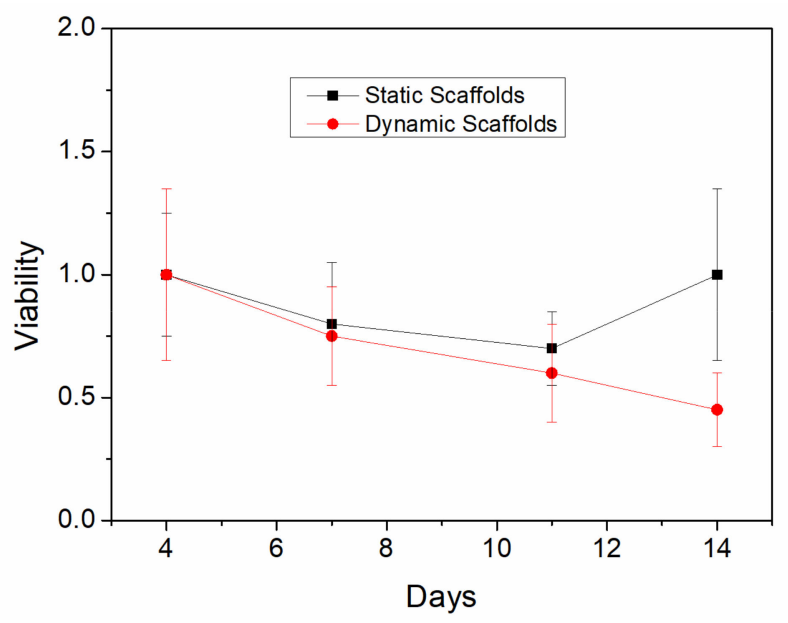

Figure 3. Cell viability of the PCL/elastin scaffolds after a static and dynamic protocol in a bioreactor.

Both groups showed a decrease in viability at 7 and 11 days of culture. However, on the last day of culture, viability growth was observed for the static controls, while in the dynamic scaffolds the viability continued to decrease. These results suggest that cells may have detached from the dynamic scaffold during their culture in the bioreactor to a greater extent compared to the static controls, due to the continuous tension and contraction movements, which may influence the feasibility results. The statistical test performed between the groups was the Mann-Whitney test, which revealed only significant differences between the groups on day 14 . Nevertheless, it is worth mentioning that PCLelastin scaffolds always allow greater cell viability than PCL systems, where viability is around $0.3-0.5$ after $4-7$ days $[40,41]$.

\subsection{2. "In Vivo" Evaluation}

H\&E Staining

During the histological study, the variables described in Section 2.3.4 were analyzed (Table 2 ). In most cases there was a slightly acute inflammatory process $(80 \%)$, with more cases of higher and chronic inflammation in the static controls. Fibroblastic proliferation and collagen formations were also mostly slight and somewhat higher in the static con- 
trols. In addition, foci of neovascularization were found, especially in dynamic scaffolds, which may lead to think that, with a longer period of implantation, these foci may be larger. In all cases, the inflammation caused was similar to that produced by PCL systems, although fibroblastic proliferation and collagen formations indicate that the incorporation of elastin in the scaffolds improves the patient's reaction to them, not generating excessive encapsulation of the biomaterial, which may cause a malfunction of the scaffold [41].

Table 2. Summary of the different parameters measured during the biological evaluation of the static and dynamic PCL/elastin scaffolds: acute inflammation, chronic inflammation, collagen deposition, fibroblast activity and neovascularization.

\begin{tabular}{ccccccccccc}
\hline Parameters & \multicolumn{2}{c}{ Acute Inflammation } & \multicolumn{2}{c}{ Chronic Inflammation } & \multicolumn{2}{c}{ Collagen Deposition } & \multicolumn{2}{c}{ Fibroblast ACTIVITY } & Neovascularization \\
\hline \multirow{2}{*}{ Grade } & Static & Dynamic & Static & Dynamic & Static & Dynamic & Static & Dynamic & Static & Dynamic \\
Slight & Scaffolds & Scaffolds & Scaffolds & Scaffolds & Scaffolds & Scaffolds & Scaffolds & Scaffolds & Scaffolds & Scaffolds \\
Moderate & 8 & 8 & 5 & 6 & 5 & 7 & 5 & 7 & 7 & 5 \\
Severe & 1 & 2 & 4 & 3 & 4 & 1 & 5 & 1 & 3 & 3 \\
TOTAL & 10 & 10 & 1 & 1 & 1 & 2 & 0 & 10 & 10 & 10 \\
\hline
\end{tabular}

On the one hand, the static controls presented $20 \%$ of moderate-severe acute inflammation, increasing this figure in chronic inflammation to $70 \%$. Moderate-severe fibrosis was present in half of the scaffolds and only $30 \%$ had moderate neovascularization. On the other hand, the dynamic scaffolds presented only $20 \%$ of moderate-severe acute inflammation, increasing in chronic inflammation to $40 \%$. Fibrosis was slight in $70 \%$ of the cases, and half of the scaffolds had moderate-severe neovascularization.

Based on Figure 4, the assessment of skeletal muscle creation reveals that, although the static samples (Figure 4A) and the dynamic samples (Figure 4B) show good cell viability, the cells observed in both groups presented incomplete differentiation, that is, they were not muscle fibers.
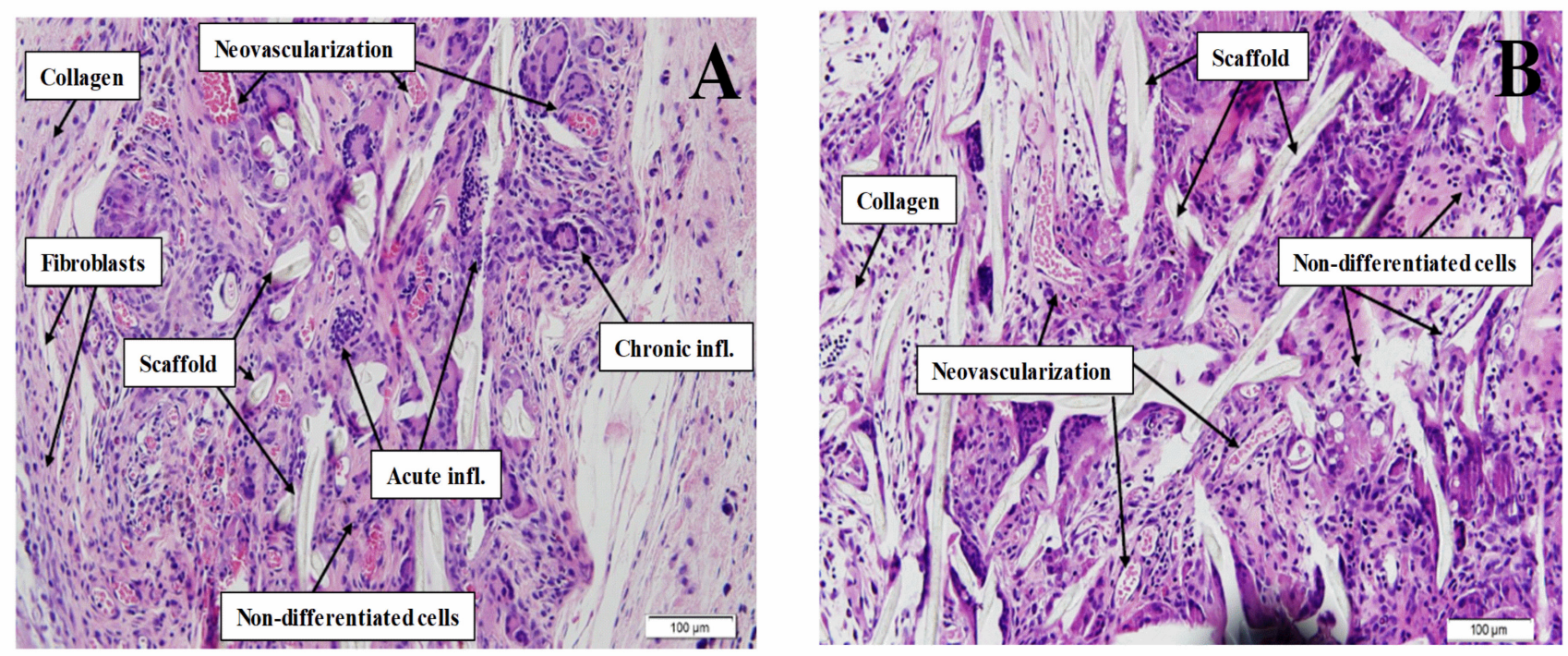

Figure 4. H\&E photomicrographs (magnification of $2 \times$ ) of the (A) static and (B) dynamic PCL/elastin scaffolds seeded with cells. Different aspects were shown with arrows: collagen formation, neovascularization, undifferentiated cells, inflammations and marks of the presence of the scaffold.

Immunohistochemistry

Regarding the immunohistochemical study, the images shown in Figure 5 reveal the presence of stained nuclei due to their differentiation. However, for both static samples (Figure 5A) and dynamic samples (Figure 5B), the microscopic assessment reveals that differentiation had not been complete due to incomplete maturation. No pathological differences were found between the static controls and the implanted dynamic scaffolds. 

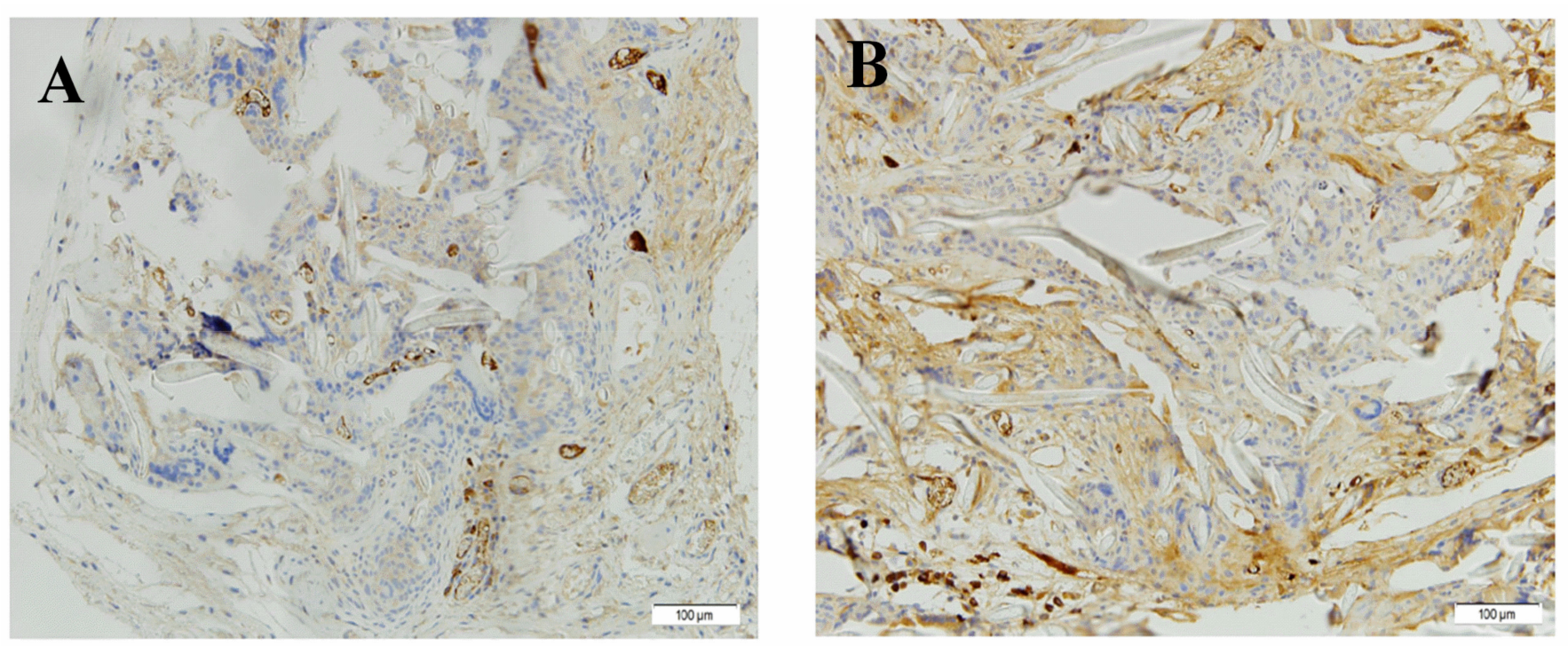

Figure 5. SMA antibody immunohistochemistry (magnification of $20 \times$ ) of the (A) static and (B) dynamic PCL/elastin scaffolds seeded with cells.

\section{Conclusions}

Hybrid nanofibrous PCL/elastin scaffolds with a huge potential for their application in tissue engineering were obtained by electrospinning. The addition of elastin to PCL-based scaffolds produced more hydrophilic scaffolds with a smaller mean fiber size, although with higher Young's modulus and maximum stress. In contrast, the formed structures were less deformable due to their lower strain at break. All this caused the incorporation of elastin in the systems to improve their biocompatibility.

According to the biological results, the in vitro creation of muscle tissue in an immature phase was shown. An increase in viability in the static controls versus the dynamic scaffolds was observed during the last phase of in vitro culture. Among in vivo analyses, fibroblast activity and collagen deposition were similar in both groups, since the materials used in both types of scaffolds were identical. Lastly, neovascularization was greater in dynamic scaffolds due to the positive effect of dynamic stimulation in the bioreactor, which is an encouraging result to continue working with these systems.

Further studies will encompass the development of the in vitro experimental phase to obtain more mature muscle tissue prior to implantation. To this end, the next step will be to optimize the dynamic stimulation protocol of the bioreactor, increasing the culture time, adding pauses to the stimulation and optimizing the stimulation speed. All this can improve their implementation as related biomaterials for the regeneration of muscular tissue in digestive applications (i.e., intestine, stomach or esophagus).

Author Contributions: Conceptualization, V.P.-P. and P.V.; methodology, V.P.-P., F.d.l.P. and A.R.; software, V.P.-P. and M.J.-R.; validation, F.d.l.P. and A.R., formal analysis, V.P.-P. and M.J.-R.; investigation, V.P.-P. and P.V.; resources, F.d.l.P. and A.R.; data curation, V.P.-P. and P.V., writing-original draft preparation, V.P.-P. and M.J.-R.; writing—review and editing, A.R.; visualization, V.P.-P. and A.R.; supervision, F.d.l.P. and A.R.; project administration, A.R.; funding acquisition, A.R. All authors have read and agreed to the published version of the manuscript.

Funding: This work is part of a research project sponsored by MICINN from the Spanish Government (Ref. RTI2018-097100-B-C21).

Institutional Review Board Statement: The study was conducted according to the guidelines of the Declaration of Helsinki, and approved by the Ethics Committee of the Investigation of Hospital Universitario Virgen del Rocío (protocol code IACUC and date of approval 11/2018).

Informed Consent Statement: Not applicable. 
Data Availability Statement: The data presented in this study are available on request from the corresponding author.

Acknowledgments: The authors also acknowledge the University of Seville for the VPPI-US grant of Victor M. Perez-Puyana. Part of this work was carried out thanks to a research stay financially supported by the program "Estancias breves en España y en el extranjero para beneficiarios de Becas predoctorales o PIF de la US y de Becas de la Fundación Cámara" from the University of Seville.

Conflicts of Interest: The authors declare no conflict of interest.

\section{References}

1. Brown, R.P. Allowable limits for toxic leachables: Practical use of ISO 10993-17 standard. The recommendations offered in this chapter should not be construed as guidance from the US Food and Drug Administration (FDA). The mention of commercial products, their sour. In Biocompatibility and Performance of Medical Devices; Biomatech/Elsevier: Sawston, UK, 2012 ; pp. 95-119.

2. Lalan, S.; Pomerantseva, I.; Vacanti, J.P. Tissue Engineering and Its Potential Impact on Surgery. World J. Surg. 2001, 25, 1458-1466. [CrossRef]

3. Ebrahimi, M.; Botelho, M.G.; Dorozhkin, S.V. Biphasic calcium phosphates bioceramics (HA/TCP): Concept, physicochemical properties and the impact of standardization of study protocols in biomaterials research. Mater. Sci. Eng. C 2017, 71, 1293-1312. [CrossRef]

4. Kobayashi, M.; Kawase, T.; Horimizu, M.; Okuda, K.; Wolff, L.F.; Yoshie, H. A proposed protocol for the standardized preparation of PRF membranes for clinical use. Biologicals 2012, 40, 323-329. [CrossRef]

5. Zuidema, J.M.; Rivet, C.J.; Gilbert, R.J.; Morrison, F.A. A protocol for rheological characterization of hydrogels for tissue engineering strategies. J. Biomed. Mater. Res. Part B Appl. Biomater. 2014, 102, 1063-1073. [CrossRef]

6. Xing, J.; Lu, Y.; Cui, Y.; Zhu, X.; Luo, F.; Xie, Z.; Wu, X.; Deng, M.; Xu, J.; Hou, T. A Standardized and Quality-Controllable Protocol of Constructing Individual Tissue-Engineered Grafts Applicable to Treating Large Bone Defects. Tissue Eng. Part C Methods 2019, 25, 137-147. [CrossRef]

7. Paliwal, P.; Pishesha, N.; Wijaya, D.; Conboy, I.M. Age dependent increase in the levels of osteopontin inhibits skeletal muscle regeneration. Aging 2012, 4, 553-566. [CrossRef]

8. Koning, M.; Harmsen, M.C.; van Luyn, M.J.A.; Werker, P.M.N. Current opportunities and challenges in skeletal muscle tissue engineering. J. Tissue Eng. Regen. Med. 2009, 3, 407-415. [CrossRef]

9. Liao, H.; Zhou, G.-Q. Development and progress of engineering of skeletal muscle tissue. Tissue Eng. Part B. Rev. 2009, 15, 319-331. [CrossRef] [PubMed]

10. Wang, B.; Wang, G.; To, F.; Butler, J.R.; Claude, A.; McLaughlin, R.M.; Williams, L.N.; de Jongh Curry, A.L.; Liao, J. Myocardial scaffold-based cardiac tissue engineering: Application of coordinated mechanical and electrical stimulations. Langmuir 2013, 29, 11109-11117. [CrossRef]

11. Arrigoni, C.; Petta, D.; Bersini, S.; Mironov, V.; Candrian, C.; Moretti, M. Engineering complex muscle-tissue interfaces through microfabrication. Biofabrication 2019, 11, 032004. [CrossRef]

12. Chen, G.; Ushida, T.; Tateishi, T. Scaffold Design for Tissue Engineering. Macromol. Biosci. 2002, 2, 67-77. [CrossRef]

13. Johnson, J.; Ghosh, A.; Lannutti, J. Microstructure-property relationships in a tissue-engineering scaffold. J. Appl. Polym. Sci. 2007, 104, 2919-2927. [CrossRef]

14. Minuth, W.W.; Schumacher, K.; Strehl, R.; Kloth, S. Physiological and cell biological aspects of perfusion culture technique employed to generate differentiated tissues for long term biomaterial testing and tissue engineering. J. Biomater. Sci. Polym. Ed. 2000, 11, 495-522. [CrossRef]

15. Stoppel, W.L.; Ghezzi, C.E.; McNamara, S.L.; Black, L.D., III; Kaplan, D.L. Clinical Applications of Naturally Derived BiopolymerBased Scaffolds for Regenerative Medicine. Ann. Biomed. Eng. 2015, 43, 657-680. [CrossRef]

16. Riboldi, S.A.; Sampaolesi, M.; Neuenschwander, P.; Cossu, G.; Mantero, S. Electrospun degradable polyesterurethane membranes: Potential scaffolds for skeletal muscle tissue engineering. Biomaterials 2005, 26, 4606-4615. [CrossRef]

17. Patrício, T.; Domingos, M.; Gloria, A.; Bártolo, P. Characterisation of PCL and PCL/PLA Scaffolds for Tissue Engineering. Procedia CIRP 2013, 5, 110-114. [CrossRef]

18. Farrugia, B.L.; Brown, T.D.; Upton, Z.; Hutmacher, D.W.; Dalton, P.D.; Dargaville, T.R. Dermal fibroblast infiltration of poly( $\varepsilon-$ caprolactone) scaffolds fabricated by melt electrospinning in a direct writing mode. Biofabrication 2013, 5, 025001. [CrossRef]

19. Siddiqui, N.; Asawa, S.; Birru, B.; Baadhe, R.; Rao, S. PCL-Based Composite Scaffold Matrices for Tissue Engineering Applications. Mol. Biotechnol. 2018, 60, 506-532. [CrossRef]

20. Kundu, J.; Shim, J.-H.; Jang, J.; Kim, S.-W.; Cho, D.-W. An additive manufacturing-based PCL-alginate-chondrocyte bioprinted scaffold for cartilage tissue engineering. J. Tissue Eng. Regen. Med. 2015, 9, 1286-1297. [CrossRef]

21. Yeo, M.; Kim, G. Nano/microscale topographically designed alginate/PCL scaffolds for inducing myoblast alignment and myogenic differentiation. Carbohydr. Polym. 2019, 223, 115041. [CrossRef]

22. Choi, J.S.; Lee, S.J.; Christ, G.J.; Atala, A.; Yoo, J.J. The influence of electrospun aligned poly(€-caprolactone)/collagen nanofiber meshes on the formation of self-aligned skeletal muscle myotubes. Biomaterials 2008, 29, 2899-2906. [CrossRef] 
23. Aguirre-Chagala, Y.E.; Altuzar, V.; León-Sarabia, E.; Tinoco-Magaña, J.C.; Yañez-Limón, J.M.; Mendoza-Barrera, C. Physicochemical properties of polycaprolactone/collagen/elastin nanofibers fabricated by electrospinning. Mater. Sci. Eng. C 2017, 76, 897-907. [CrossRef]

24. Saderi, N.; Rajabi, M.; Akbari, B.; Firouzi, M.; Hassannejad, Z. Fabrication and characterization of gold nanoparticle-doped electrospun PCL/chitosan nanofibrous scaffolds for nerve tissue engineering. J. Mater. Sci. Mater. Med. 2018, 29, 134. [CrossRef]

25. Swindle-Reilly, K.E.; Paranjape, C.S.; Miller, C.A. Electrospun poly(caprolactone)-elastin scaffolds for peripheral nerve regeneration. Prog. Biomater. 2014, 3, 20. [CrossRef]

26. Knightly, J.J.; Agostino, D.; Cliffton, E.E. The effect of fibrinolysin and heparin on the formation of peritoneal adhesions. Surgery 1962, 52, 250-258. [CrossRef]

27. Kohn, D.F.; Martin, T.E.; Foley, P.L.; Morris, T.H.; Swindle, M.M.; Vogler, G.A.; Wixson, S.K. Guidelines for the assessment and management of pain in rodents and rabbits. J. Am. Assoc. Lab. Anim. Sci. 2007, 46, 97-108.

28. Yoo, H.S.; Kim, T.G.; Park, T.G. Surface-functionalized electrospun nanofibers for tissue engineering and drug delivery. Adv. Drug Deliv. Rev. 2009, 61, 1033-1042. [CrossRef]

29. Yang, Y.; Zhu, X.; Cui, W.; Li, X.; Jin, Y. Electrospun Composite Mats of Poly [(D,L-lactide)-co-glycolide] and Collagen with High Porosity as Potential Scaffolds for Skin Tissue Engineering. Macromol. Mater. Eng. 2009, 294, 611-619. [CrossRef]

30. Ng, R.; Zhang, X.; Liu, N.; Yang, S.-T. Modifications of nonwoven polyethylene terephthalate fibrous matrices via NaOH hydrolysis: Effects on pore size, fiber diameter, cell seeding and proliferation. Process Biochem. 2009, 44, 992-998. [CrossRef]

31. Wang, L.; Wu, Y.; Guo, B.; Ma, P.X. Nanofiber Yarn/Hydrogel Core-Shell Scaffolds Mimicking Native Skeletal Muscle Tissue for Guiding 3D Myoblast Alignment, Elongation, and Differentiation. ACS Nano 2015, 9, 9167-9179. [CrossRef]

32. Whited, B.M.; Rylander, M.N. The influence of electrospun scaffold topography on endothelial cell morphology, alignment, and adhesion in response to fluid flow. Biotechnol. Bioeng. 2014, 111, 184-195. [CrossRef] [PubMed]

33. Jia, L.; Prabhakaran, M.P.; Qin, X.; Kai, D.; Ramakrishna, S. Biocompatibility evaluation of protein-incorporated electrospun polyurethane-based scaffolds with smooth muscle cells for vascular tissue engineering. J. Mater. Sci. 2013, 48, 5113-5124. [CrossRef]

34. Elzein, T.; Nasser-Eddine, M.; Delaite, C.; Bistac, S.; Dumas, P. FTIR study of polycaprolactone chain organization at interfaces. J. Colloid Interface Sci. 2004, 273, 381-387. [CrossRef] [PubMed]

35. Annabi, N.; Fathi, A.; Mithieux, S.M.; Martens, P.; Weiss, A.S.; Dehghani, F. The effect of elastin on chondrocyte adhesion and proliferation on poly ( $\epsilon$-caprolactone)/elastin composites. Biomaterials 2011, 32, 1517-1525. [CrossRef]

36. Debelle, L.; Alix, A.J.P.; Wei, S.M.; Jacob, M.-P.; Huvenne, J.-P.; Berjot, M.; Legrand, P. The secondary structure and architecture of human elastin. Eur. J. Biochem. 1998, 258, 533-539. [CrossRef]

37. Hendrikson, W.J.; Rouwkema, J.; Van Blitterswijk, C.A.; Moroni, L. Influence of PCL molecular weight on mesenchymal stromal cell differentiation. RSC Adv. 2015, 5, 54510-54516. [CrossRef]

38. Kubiak, K.J.; Mathia, T.G. Anisotropic Wetting of Hydrophobic and Hydrophilic Surfaces-Modelling by Lattice Boltzmann Method. Procedia Eng. 2014, 79, 45-48. [CrossRef]

39. Zou, L.; Zhang, Y.; Liu, X.; Chen, J.; Zhang, Q. Biomimetic mineralization on natural and synthetic polymers to prepare hybrid scaffolds for bone tissue engineering. Colloids Surfaces B Biointerfaces 2019, 178, 222-229. [CrossRef]

40. Cho, S.J.; Jung, S.M.; Kang, M.; Shin, H.S.; Youk, J.H. Preparation of hydrophilic PCL nanofiber scaffolds via electrospinning of PCL/PVP-b-PCL block copolymers for enhanced cell biocompatibility. Polymer 2015, 69, 95-102. [CrossRef]

41. Lee, J.-J.; Yu, H.-S.; Hong, S.-J.; Jeong, I.; Jang, J.-H.; Kim, H.-W. Nanofibrous membrane of collagen-polycaprolactone for cell growth and tissue regeneration. J. Mater. Sci. Mater. Med. 2009, 20, 1927-1935. [CrossRef] 